\title{
Cobertura de las necesidades promedio y emigración
}

ILEANA Pinto

Mónica Velado

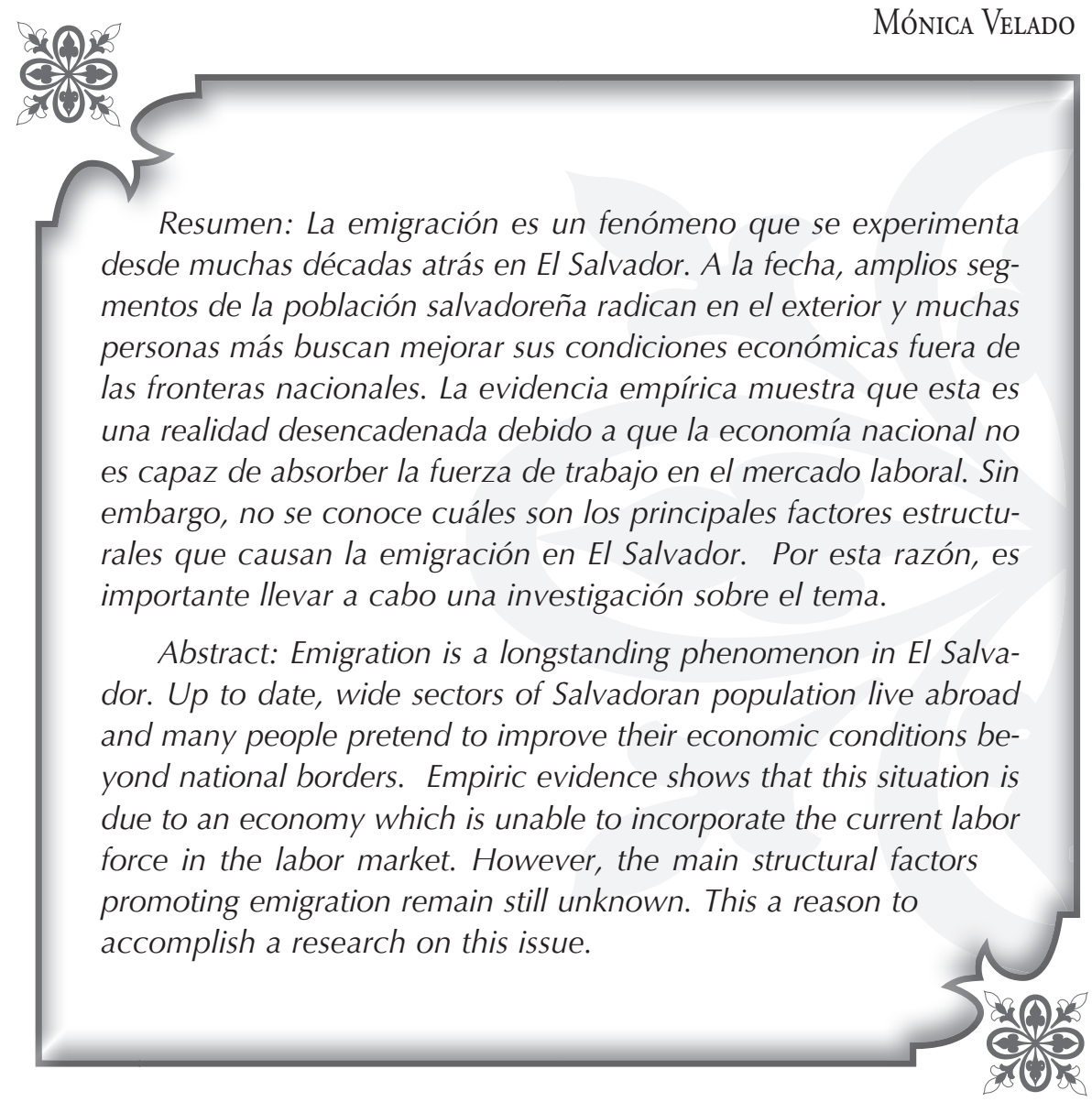




\section{Introducción}

La migración es uno de los temas más analizados en los últimos años, dado que es un fenómeno de enorme importancia, en especial por los altos flujos migratorios que van desde América Latina hacia Estados Unidos.

La temática ha generado múltiples escenarios de índole económico y social para las personas que migran, sus familias y las sociedades de origen y destino. Al mismo tiempo se trata de una realidad en la que se imponen restricciones físicas y legales establecidas por los Estados de destino, donde el ingreso a su territorio es cada vez más difícil. Muestra de ello es la aprobación de la "Ley de protección fronteriza, antiterrorismo y control de la inmigración ilegal" en los Estados Unidos, y las enormes redadas en contra de los migrantes ilegales, en las cuales se llega a irrespetar los derechos de los migrantes de manera preocupante.

En El Salvador, este es un fenómeno que se experimenta desde muchas décadas atrás, el Informe sobre Desarrollo Humano El Salvador 2005, lo centra desde inicios del siglo pasado (PNUD, 2005). La denominada "frontera agrícola", provocó el desplazamiento de un importante número de población rural, generando la migración urbana, y de esta, la migración externa.
A la fecha, amplios segmentos de la población salvadoreña radican en el exterior y un número no determinado aún busca alcanzar una oportunidad de mejorar sus condiciones económicas y materiales orientándose a la búsqueda de trabajo fuera de las fronteras nacionales.

La evidencia empírica muestra que esta es una realidad desencadenada debido a que la economía nacional no es capaz de absorber la fuerza de trabajo en el mercado laboral formal, en donde se le otorgue al trabajador el ingreso necesario para la cobertura de las necesidades de su familia.

Sin embargo, no se conoce el o los principales factores estructurales que causan la migración externa en El Salvador. Por esta razón, parece importante llevar a cabo una investigación sobre el tema.

El estudio se divide en tres capítulos, el primero se destina a presentar algunos desarrollos teóricos existentes sobre el análisis de la migración. El esfuerzo es proponer una explicación teórica que defina de manera más acertada el fenómeno de las migraciones externas en El Salvador.

En el segundo capítulo se presentan las principales consecuencias macroeconómicas y mi- 
croeconómicas que han generado las migraciones externas del país a lo largo de los últimos años, así como la relación de los efectos y la funcionalidad con el modelo económico estructural.
El tercer capítulo se destina a tratar de comprobar-mediante un modelo econométrico- que la falta de cobertura del valor de la fuerza de trabajo es la principal determinante de índole estructural que incentiva la migración externa en El Salvador.

\section{Revisión de algunas teorías o modelos sobre migración}

Diversas teorías explican la migración adaptándose a la realidad de las economías subdesarrolladas. Algunas de ellas se exponen a continuación.

\section{Modelo dual de Lewis ${ }^{1}$}

Lewis expone la dualidad existente en los países en desarrollo: hay en ellos dos sectores económicos, el rural o tradicional y el sector urbano o moderno. El sector rural se caracteriza por ser superpoblado, con excedente de mano de obra y de baja productividad. El sector urbano se caracteriza por ser industrial y de alta productividad. En el sector moderno, la productividad del trabajo es mucho mayor que en el campo, esto permite que exista ahorro e inversión lo que se traducirá en un aumento sostenido de la demanda de trabajadores.

El proceso de desarrollo se caracterizará por una transferencia de mano de obra desde el sector tradicional al moderno, hasta que el total del excedente de mano de obra rural sea absorbido por el urbano.
Se produce así en el sector industrial un "círculo virtuoso" en donde el ahorro lleva a la inversión y esta a su vez se traduce en más empleo, por lo que el crecimiento del sector industrial-urbano está garantizado hasta que el sector de baja productividad quede despoblado, lo que implicará el final de la situación de subdesarrollo.

Según este modelo la causa de la migración es la diferencia de salarios entre el lugar de origen y de destino.

\section{Teoría del Libre Comercio y Migración}

De acuerdo a esta teoría, las reformas comerciales contribuyen a incrementar la migración por medio de dos procesos, ya sea porque dan lugar a un desplazamiento de fuerza de trabajo de los sectores más vulnerables, o paradójicamente, porque las nuevas oportunidades económicas permiten a los trabajadores acumular los recursos necesarios para emigrar. Cualquiera de estos dos procesos podría incrementar la 
emigración tanto en el corto como en el mediano plazo. Pero conforme el libre comercio contribuya a reducir las diferencias económicas y salariales entre dos países, la emigración tendería a reducirse.

Esta teoría tiende a prevalecer cuando se reúnen las siguientes condiciones: Cuando hay oportunidades laborales en otro país que ejercen atracción sobre los emigrantes; cuando las presiones migratorias se intensifican como consecuencia de los ajustes económicos producto de la liberalización comercial; cuando las redes sociales y familiares apoyan los movimientos internacionales.

Teoría de la movilidad internacional del trabajo

La movilidad internacional del trabajo supone que las economías se clasifican según la abundancia de factores que poseen, así tenemos economías con capital abundante y economías con trabajo abundante.

Un país capital abundante como Estados Unidos o los países Europeos, pueden importar bienes intensivos en trabajo o empezar a emplear trabajadores inmigrantes. Un país con trabajo abundante (como El Salvador) puede importar bienes intensivos en capital o puede adquirir capital tomándolo prestado del extranjero.
Esta teoría supone que existe un libre movimiento del factor trabajo a nivel mundial, el cual tendería a ser un mecanismo estabilizador de salarios reales.

Teoría de la nueva economía de la migración según la carencia relativa

Explica que las decisiones de emigrar se toman por unidades como familia y no como autores individuales, por lo que los hogares recurren a la migración de sus miembros con el fin de diversificar sus fuentes de ingresos, reducir riesgos y realizar nuevas inversiones.

En los países desarrollados existen programas gubernamentales, compañías de seguros y programas de crédito para que los hogares minimicen los riesgos y realicen nuevas inversiones. Las familias de los países subdesarrollados deben buscar otras salidas dado que esos mecanismos institucionales no existen, son inaccesibles o son muy costosos. Esos vacíos institucionales son fallas del mercado que estimulan la migración.

Por tanto, esta teoría plantea que la existencia de diferenciales salariales no es una condición necesaria para dar lugar a desplazamientos hacia el exterior, sino que se dan para minimizar los riesgos y para aliviar las restricciones que imponen una amplia variedad de imperfecciones de los mercados en los países de origen. 
Modelo de probabilidad de empleo de Harris-Todaro

Este modelo fue realizado para examinar el caso de países menos desarrollados, el objetivo es explicar el hecho que - a pesar de la existencia de productos marginales positivos en agricultura y de niveles importantes del desempleo urbanola migración de trabajadores desde el sector rural al urbano continúa y parece acelerarse.

Para estos autores la decisión de emigrar depende del diferencial de ingresos entre el lugar de origen y el de destino. Este modelo, basado en las aportaciones de Lewis, trata de dar explicación al desempleo urbano creciente, el supuesto dominante es que la migración rural - urbana continuará mientras los ingresos reales urbanos esperados excedan al salario real de la agricultura.

El modelo del proceso migratorio y el desarrollo económico

En esta concepción, el concepto de migración se ve estrechamente relacionado con el desarrollo económico, el cual a su vez depende en esta teoría de la cobertura del valor de la fuerza de trabajo.

Para explicar esto, el autor ${ }^{2}$ establece dos conceptos esenciales basados en la teoría sobre el Capital de Marx: fuerza de trabajo es el conjunto de facultades físicas e intelectuales que posee un hombre y que debe poner en movimiento para producir cosas útiles; y valor de la fuerza de trabajo es la cobertura del desgaste en la fuerza de trabajo del individuo que debe ser repuesta al haber producido bienes. Esta cobertura depende de los bienes de manutención básicos, las necesidades sociales, morales y de carácter histórico de los trabajadores.

Si el salario que paga el capitalista al trabajador, en su afán de obtener el mayor lucro posible, es fijado por debajo del valor de la fuerza de trabajo, la capacidad productiva y la eficiencia de esta comienza a reducirse $y$, por tanto, los avances técnicos que se han alcanzado no se aprovechan plenamente debido a las razones siguientes: se genera un deterioro de las condiciones nutricionales, se forma un deterioro psicosocial, que se refleja en problemas del sistema nervioso y en la reducción del nivel de educación, mermando así la capacidad de aprovechamiento de los programas de capacitación laboral y, por tanto, de las tecnologías; además se presenta el fenómeno de la migración, lo que equivale a la pérdida del recurso humano, reduciendo las potencialidades de la economía.

De acuerdo a lo expuesto, una vez que el emigrante se ha adaptado al lugar de destino, se puede decir que el recurso de la fuerza de trabajo se ha perdido y las potencialidades de la economía de origen se ven reducidas. Pero puede ocurrir que la 


\section{을 mano de obra que ha migrado no se vea totalmente adaptada en el país destino, en este caso es muy proba- ble que el vínculo económico con el lugar de origen no desaparezca,. Esto explica el fenómeno de las remesas.}

\subsection{Crítica a las teorías planteadas}

La mayoría de las teorías que se han expuesto anteriormente concuerdan que las motivaciones para migrar de los individuos o las familias están relacionadas con la búsqueda de mejores condiciones económicas y niveles de calidad de vida más altos.

Sin embargo, algunas de ellas no se apegan a la realidad en su totalidad, como es el caso del Modelo de Lewis, que no toma en cuenta la tecnología como factor desplazador de mano de obra, un ejemplo de ello es la producción de automóviles, en donde la mayoría de sus procesos se han mecanizado; por tal razón, este factor no permite que en el sector urbano se absorba toda la mano de obra rural que ha migrado, generando que este remanente de personas se establezca en las urbes viviendo en condiciones de alta precariedad.

Otro caso es la Teoría de la Movilidad Internacional del Trabajo, la cual supone la libre movilidad de este factor, pero el supuesto no se cumple en la práctica, ya que muchos países del centro han incrementado las trabas a la migración pro- veniente de los países subdesarrollados, por ejemplo: La emigración de los países latinoamericanos hacia Estados Unidos, en donde las leyes son cada vez más rígidas respecto a la recepción y permanencia de migrantes, adicionalmente no existe la igualdad de derechos laborales entre migrantes y nacionales.

Un tercer caso es el modelo de Probabilidad de Empleo de HarrisTodaro que no explica porqué la población sigue migrando sin que el previsible equilibrio entre los salarios de los dos países se establezca.

Por lo tanto, es necesario plantear un modelo que tome en cuenta variables más profundas de las condiciones de vida de los países expulsores, las cuales podrían ser las causas principales de la migración.

Hay dos teorías en concreto que explican el fenómeno como consecuencia del mismo sistema económico, la teoría de la Nueva Economía de la Migración y el Modelo sobre el Proceso Migratorio y el DesarroIlo Económico. La primera toma en cuenta las necesidades institucionales que las familias tienen en el lugar de origen, y la migración como una decisión tomada como unidad familiar; la segunda teoría tiene como enfoque principal la falta de cobertura del valor de la fuerza de trabajo. Por lo tanto, en el próximo apartado se desarrollará un modelo basado en estas teorías. 


\section{Modelo de cobertura de las necesidades promedio y migración}

El fenómeno migratorio, tal como se está viendo en los países subdesarrollados, enfrenta a los individuos y a las familias ante una decisión difícil de tomar, y a pesar de que cada una de ellas pueda tener un mundo de razones para llevar a cabo este proyecto, es evidente que existe entre estas una raíz común, es precisamente esta raíz la que se pretende explicar con este apartado.

El modelo de cobertura de las necesidades promedio y migración se basa en el supuesto que las familias deciden enviar a uno o más de sus miembros hacia el exterior, en búsqueda de trabajo para aumentar los ingresos familiares y así cubrir la canasta de mercado que no puede ser satisfecha en su país de origen.

Por tanto la migración dependerá en gran medida de la cobertura del valor de la fuerza de trabajo ${ }^{3}$ que exista en las economías. Esta concierne a la satisfacción de las necesidades promedio que las familias requieren para sostenerse y reproducirse en condiciones dignas y estables, es decir en condiciones socialmente aceptables, tales como una alimentación completa y balanceada, vivienda, vestuario, salud, educación, servicios básicos, transporte, etc., todas estas representadas en la canasta de mercado4 ${ }^{4}$.
Es claro que el grado de cobertura de estas necesidades depende principalmente del ingreso que una familia logre obtener, ya sea del mercado laboral formal como informal. El no obtener el grado esperado $^{5}$ de esta cobertura puede empujar a las familias a la búsqueda de alternativas fuera de los límites del empleo formal a fin de lograr complementar con las remuneraciones derivadas de un trabajo informal.

Mientras una familia logre sostener un alto grado de cobertura de la canasta de mercado, la tendencia de sus miembros a migrar será mínima. Un menor grado de cobertura representará una fuerte razón para buscar fuera de las fronteras nacionales las oportunidades que le permitan al individuo obtener los suficientes ingresos para lograr satisfacer las necesidades que su familia requiere, para llevar una vida en condiciones socialmente aceptables.

Uno de los aspectos principales para no lograr esta cobertura es el alto grado de desempleo que existe en los países subdesarrollados. EI desempleo se refiere al contingente de personas en edad de trabajar que no tienen empleo y lo buscan activamente. Es importante aclarar que el criterio para definir la edad mínima para trabajar depende de la situación particular de cada país, en 
el caso de El Salvador, por ejemplo, esta es de 14 años y más.

El desempleo puede tener dos modalidades: el desempleo abierto $y$ el desempleo equivalente. El desempleo abierto abarca a todas las personas que no cuentan con ningún tipo de empleo y se encuentran disponibles a aceptar uno. El desempleo equivalente se deriva del subempleo, y consiste en la suma de todos aquellos remanentes de desempleo que forman parte del subempleo. La tasa de desempleo equivalente representa el porcentaje de subempleados convertidos al equivalente de desempleados, con respecto a la población económicamente activa.

Una familia que se encuentre en problemas de desempleo no podrá obtener los ingresos para cubrir las necesidades mínimas para su subsistencia y reproducción, y mucho menos le permitirán llevar una calidad de vida en la que logre cubrir todas sus necesidades. Por tanto, dado que dentro del país de origen no es posible encontrar un empleo adecuado, algunos de los miembros del hogar se encontraran en la necesidad de recurrir a la migración, buscando trabajo en otros países que cuentan con una economía más rica y en donde las oportunidades son mayores.

De acuerdo a lo anterior, se esperaría que un incremento en el número de desempleados y desempleados equivalentes, empuje a estas personas a migrar con el fin de encontrar en el país de destino la fuente de ingresos que le permita sostener a su familia en mejores condiciones de vida, de igual forma sucedería si existiese una disminución de sus ingresos aunque no aumente el desempleo o el desempleo equivalente.

Asimismo, existen tres aspectos ligados entre sí que influyen en la tendencia migratoria, uno de ellos es la pobreza. La pobreza es un fenómeno complejo para el cual existen múltiples definiciones y maneras de medirla. Tradicionalmente se ha definido la pobreza como privación material, medida mediante el ingreso o el consumo del individuo o la familia. En este caso se habla de pobreza extrema o pobreza absoluta como la falta de ingreso necesario para satisfacer las necesidades de alimentación básica. Adicionalmente, existe la definición de pobreza relativa, que es donde el ingreso satisface las necesidades alimentarias básicas pero no necesariamente las necesidades de vestido, energía y vivienda (UNICEF, 2005).

Con fines de comparación internacional, el Banco Mundial considera en pobreza absoluta todas aquellas personas que viven con menos de $\$ 1$ diario y en pobreza relativa aquellas que viven con menos de $\$ 2$ diarios. 
El Consejo Nacional de Población de México (CONAPO) ${ }^{6}$ menciona que hay estudios empíricos realizados en diversos contextos y países del mundo en donde se menciona que los sectores más pobres no emigran. Pero pese a lo anterior es notorio que existe una relación entre la propensión a migrar y los procesos de empobrecimiento de ciertos sectores de la población que posee algún grado de solvencia económica y calificaciones para el empleo.

En este sentido, se esperaría que a ciertos niveles de pobreza los miembros de las familias tengan una mayor propensión a migrar, dado que no cuentan con los ingresos necesarios para cubrir sus necesidades a nivel local, pero sí cuentan con los recursos para llevar a cabo el proceso migratorio.

El otro aspecto es la no pobreza. Este aspecto está medido con respecto a la canasta ampliada, ya que una familia que cubra la canasta básica multiplicada por dos no se considera pobre.

La no pobreza actúa de manera similar a como lo hace la pobreza pues se esperaría que entre mayor riqueza posean las familias menor será el impulso que sus integrantes tengan de migrar, es decir, las familias con los mayores niveles de ingresos y con ingresos precarios, serán las menos propensas a migrar.
Pero la pobreza y la riqueza no deben medirse sólo según el acceso a bienes materiales y sociales. Es necesario que los individuos tengan la capacidad de utilizarlos eficazmente, para que les permita procurarse su propio bienestar, por lo tanto el tercer aspecto es la capacidad y calidad de inserción al mercado laboral.

Este aspecto está relacionado con las habilidades que posean los integrantes de la familia para insertarse de manera eficiente en el mercado laboral, en otras palabras, la capacidad de los miembros para integrarse de manera rápida y bien remunerada dentro del empleo formal, esto dependerá en gran medida del nivel de educación y edad que posean. Se prevé que un mayor nivel de educación o un nivel avanzado de estudios superiores, permitirá a los miembros del grupo familiar establecerse de manera más eficiente en un empleo formal y de esta manera recibir los ingresos necesarios para cubrir la canasta de mercado, reduciéndose así la probabilidad de migrar.

En resumen, el modelo plantea que la migración puede explicarse en 5 aspectos principales: la falta de cobertura de las necesidades "normales" de las familias, el desempleo, el nivel de pobreza de las familias, su nivel de riqueza y la capacidad y calidad de inserción de sus miembros al mercado laboral. Estos elementos están 
응 relacionados a la estructura que las
ํํ

Se pretende comprobar esta teoría a partir del estudio de la eco- nomía de El Salvador, razón por la cual en el siguiente apartado se verán aspectos generales y tendencias de la emigración salvadoreña en los últimos años.

\section{Tendencias recientes de la migración en EI Salvador}

El fenómeno de la migración externa no es un tema nuevo para El Salvador. Este suceso ha estado palpable a lo largo de la historia salvadoreña siendo impulsado por diversas razones, principalmente de índole socioeconómica.

En el país se han realizado diversos estudios para comprender el fenómeno de la migración, uno de ellos es el Informe sobre Desarrollo Humano 2005 del PNUD, en donde divide el fenómeno de la migración externa en etapas cronológicas, diferenciadas por las motivaciones de los migrantes.

Desde una presentación simplificada estas motivaciones pasan por: falta de acceso a la tierra y oportunidades de empleo en el área rural, la guerra de las cien horas con Honduras y el subsiguiente rompimiento del Mercado Común Centroamericano, el conflicto armado, escasez de empleo y de oportunidades de desarrollo de actividades productivas, crecientes niveles de desigualdad, la desaceleración económica que comenzó en 1996, la caída de los precios del café, los estragos del huracán Mitch, los dos terremotos, la delincuencia, las crecientes historias de éxito de personas que optaron por migrar en décadas anteriores, la alta inseguridad social a nivel local.

Amplios segmentos de la población salvadoreña aún busca alcanzar una oportunidad de mejorar sus condiciones económicas y materiales orientándose a la búsqueda de trabajo en el exterior. Para 2005 la cantidad de salvadoreños que emigraron diariamente ascendió a 1,070 siendo su principal destino desde los años 70, Estados Unidos. La tasa de crecimiento de los flujos migratorios entre los años 70 y 80 fue de $73 \%$, mientras que para las décadas 80 y 90 fue de $307 \%$. La tasa de crecimiento entre el 90 y 2000 se aproxima al 400\%. (PNUD, 2005: 1-5).

Según el Ministerio de Relaciones Exteriores en su informe "Salvadoreños en el Exterior" (2002) se presumía que para ese año radicaban en el exterior una población cercana a los 2.5 millones de salvadoreños distribuidos en diferentes partes del mundo; uno de cada cuatro salvadoreños se encontraba en el exterior, de ese total al menos un $94 \%$ se concentraba en EE.UU. (2.3 millones). 
Datos del Informe de Desarrollo Humano del PNUD 2005 indican que el primer millón de salvadoreños emigró entre los años de 1951 a 1998, pero solamente se requirieron 4 años más (1998-2002) para despachar el segundo millón y esta tendencia continúa incrementándose, especialmente desde la desaceleración del 96.

Producto del fenómeno migratorio laboral y de las condiciones socioeconómicas imperantes, es la elevada dependencia económica de los flujos monetarios generados por emigrantes salvadoreños que sustentan la economía de la nación, y que parecen vitales tanto para las familias como para la economía del país en su conjunto. El monto de remesas para el 2007 fue de US\$ 3,695.3 millones, suma equiparable al 93\% del total de las exportaciones del país para el mismo año y representan aproximadamente el $19 \%$ del PIB (BCR, 2008).

Tal situación se traduce en un fenómeno que se ha vuelto de magnitudes trascendentales. En este contexto se plantea la necesidad de estudiar el fenómeno de las migraciones externas, desde una perspectiva integral, teniendo en cuenta las causas y los efectos económicos y sociales que genera a la economía del país.

\section{Consecuencias de la migración}

\subsection{Efectos macroeconómicos}

El fenómeno migratorio ha sido causa de preocupación para algunos investigadores sociales a nivel internacional. Existe abundante información al respecto y el tema se ha vuelto de gran importancia actualmente, en especial porque afecta los derechos humanos de los migrantes, ya sea en el proceso de migración o en la inserción dentro de las sociedades en los países destino, como la discriminación, la trata de personas, entre otros. Otro factor derivado de las migración es el volumen que las remesas aportan a las economías latinoamericanas, solo para 2006, las remesas en América Latina ascendieron a $62,300^{7}$ millones de USD, convirtiendo a la región en el área que recibe una mayor cantidad de remesas a nivel mundial.

En los países latinoamericanos, las remesas se han convertido en flujos de dinero o capital importantes dentro del ingreso nacional. Las remesas ofrecen una ventaja frente a los flujos de capital, ya que estas tienden a incrementarse año tras año, mientras que los flujos de capital fluctúan acorde a los ciclos económicos.

La falta de oportunidades y la creciente pobreza ha convertido a la emigración en solución para más de $400,000^{8}$ centroamericanos que cada año buscan mejorar sus ingre- 
sos, para permitirles vivir mejor $y$ enviar dinero a sus familias. Para Centroamérica los montos de las remesas ascienden a importantes sumas dentro de la economía de cada uno de los países, la relación se muestra en el gráfico II-1. En la región Centroamericana, Honduras tiene la mayor relación con respecto al PIB del país, con un $21 \%$. Le sigue El Salvador, con una relación del $18 \%$.

\section{Gráfico II-1. Monto total de remesas para países de C.A. y la relación con respecto al PIB de cada país: 2007}

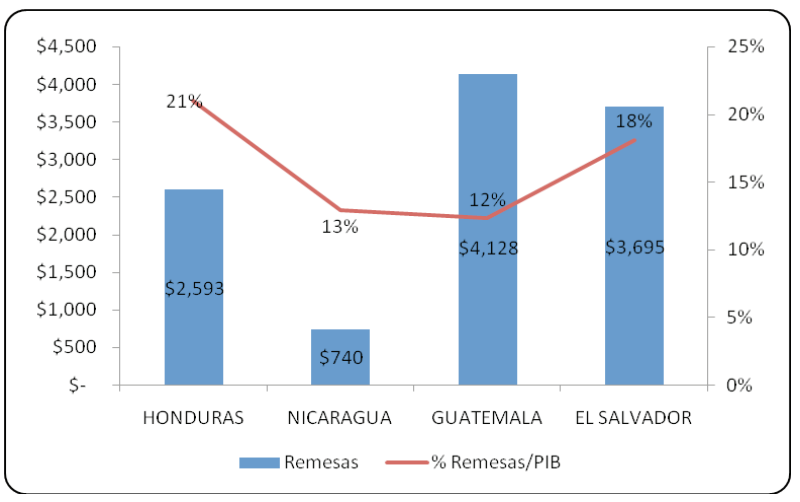

Fuente: Elaboración propia en base a Banco Centrales de cada país. Montos en Millones de USD. Datos no disponibles para Costa Rica

El Salvador, a finales de los ochenta, somete su economía a un nuevo modelo, basado en tendencias de corte neoliberal y en los ajustes estructurales derivados del Consenso de Washington, con lo que se pretendía liberalizar la economía y de esta manera impulsar el desarrollo económico.

Sin embargo, en la actualidad, la economía no necesariamente debe su sostenimiento a los ajustes realizados tal como se pretendía, sino gran parte de ella se encuentra sustentada en los flujos de divisas que los migrantes salvadoreños obtienen fuera de las fronteras del país, principalmente en Estados Unidos, y que generosamente envían a sus familiares y comunidades de origen a fin de que ellos puedan cubrir las necesidades que el país no les permite por diversos motivos, entre ellos falta de empleo, salarios por debajo de los niveles necesarios para una calidad de vida, etc. Aspectos que destacan las debilidades de las que el sistema actual dentro de El Salvador adolece, y que, con el paso del tiempo, parecen aumentar. 
El dinamismo de los flujos de remesas se ve reflejado en el crecimiento que han tenido a lo largo de los años, dicho aumento se visualiza en el gráfico II-2, donde se puede observar que en el último quinquenio la recepción de reme- sas ha incrementado aproximadamente un $91 \%$, recibiendo en el 2002 un total de 1,935.2 millones de USD, contra 3,695.3 millones de USD en el 2007, lo que se traduce en una mayor dependencia de las mismas.

\section{Gráfico II-2. Crecimiento \% por año de las remesas: 1991 - 2007}

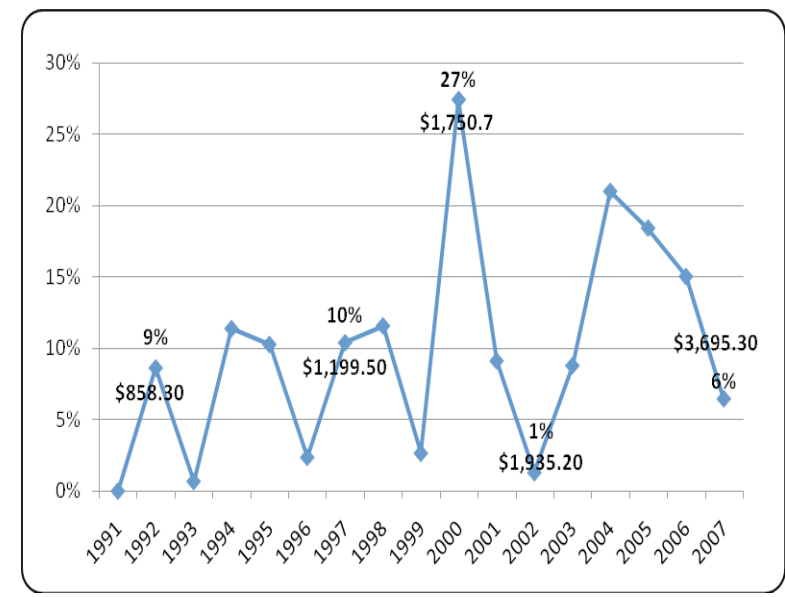

Fuente: Elaboración propia en base a BCR en línea www.bcr.gob.sv Montos en Millones de USD

Esta dependencia que el país tiene de estos flujos proviene de que las remesas son en la actualidad la principal fuente de divisas en la economía de El Salvador. En el gráfico II-3 se muestra la evolución de las principales fuentes de divisas del país, observándose que para la década de los noventa la agroexportación representaba cinco veces más que en la actualidad, mientras que las remesas han mantenido desde esos mismos años la mayor participación. Es importante aclarar que la segunda fuente de divisas es el sector maquilero que en los años noventa fue impulsado gracias a las medidas del gobierno, sin embargo, este sector viene a ser al final una prestación de servicios de factores de trabajo, en donde se importan bienes intermedios, se les agrega valor y luego son exportados, y no vienen a representar una producción totalmente generada por el país. 


\section{Gráfico II-3 Relación porcentual del total de fuentes de divisas: \\ $1978-2007$}

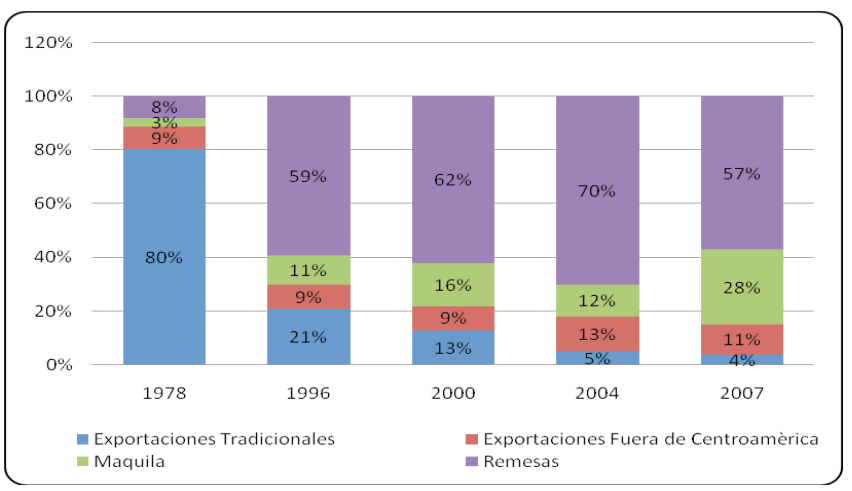

Fuente: Elaboración propia en base a BCR en línea www.bcr.gob.sv

Las políticas económicas llevadas a cabo en El Salvador en los años 90's ${ }^{9}$ lograron que el país dejara a un lado la producción y exportación de productos agrícolas, e incentivara la importación de bienes, comercio y el sector servicios. Estos sectores basan sus estrategias, para obtener mayores ganancias, en la sobreexplotación de la fuerza de trabajo, es decir, bajos salarios, largas jornadas laborales, subempleo; lo que a su vez llevó al incremento de la migración y las remesas. Esta situación viene a traducirse en una terciarización económica. Por lo tanto, el soporte de la economía, cambió de la agro exportación a las remesas, ya que para el 2007 representaron el $57 \%$ del total de divisas, contra un $4 \%$ de las exportaciones tradicionales, permitiendo cubrir los altos déficits comerciales de los últimos años, alcanzando para el 2007 un total de 4,073 millones USD.
En una economía no dolarizada, la carencia de divisas para suplir esta demanda generaría un incremento en el valor del dólar respecto a la moneda local depreciando la moneda, lo que encarece las importaciones y abarata las exportaciones, consecuentemente las importaciones se reducen, y las exportaciones se incrementan. Pero en un caso en donde la economía tiene un tipo de cambio fijo, simplemente se tendría que dejar de importar el exceso una vez se han utilizado todas las reservas internacionales, reduciendo la capacidad de consumir y de producir.

Para El Salvador, ninguno de estos dos mecanismos de ajuste han entrado en acción gracias a las entradas "gratis" de divisas internacionales, lo que se traduce en que las remesas financiaron para el 2007 aproximadamente el $43 \%{ }^{10}$ de las 
importaciones que incluyen bienes de consumo, bienes intermedios y de capital.

Además de ayudar a la balanza de pagos a través de la cuenta corriente, el fenómeno de la emigración contribuye a la economía por medios relacionados a los sectores de comercio y servicios.

Los nuevos nichos de mercado que ha generado el fenómeno migratorio, deben su existencia a la variada cantidad de servicios que los migrantes ahora utilizan dado el vínculo familiar que poseen con su país de origen. Estos sectores se han vuelto altamente dinámicos, contribuyendo de manera importante dentro del Producto Interno Bruto. Estos son las telecomunicaciones, el transporte aéreo, el mercado de transferencias, turismo, comercio de productos nostálgicos, vivienda.

El sector de Telecomunicaciones incluye la telefonía fija, móvil, de larga distancia, internet, etc. El de mayor importancia dentro de esta área es el de la telefonía móvil (Ver gráfico II-4), que en los últimos 4 años en promedio ha crecido un $48 \%$, el segundo de importancia es el internet (dedicado) con un $46 \%$.

\section{Gráfico II-4 Crecimiento de las ramas del sector telecomunicaciones: $2000-2007$}

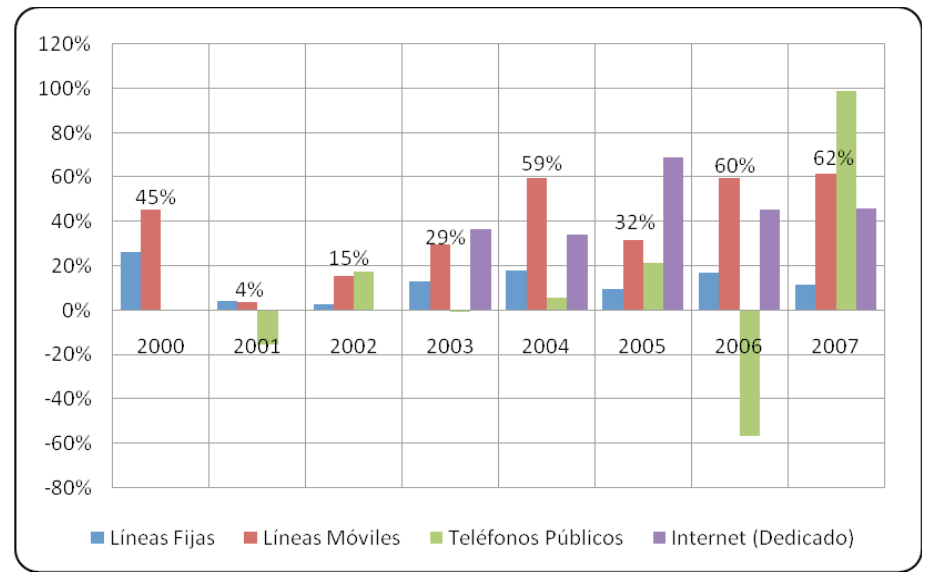

Fuente: Elaboración propia en base a BCR en línea www.bcr.gob.sv

Para el año 2000 los pagos a El Salvador por Ilamadas desde Estados Unidos ascendieron a un monto aproximado de $\$ 71$ millones; para el 2005 este monto ascendió a
\$98 millones (FCC en línea, 2007), teniendo una tasa de crecimiento de $38.3 \%$ en los 5 años. Estos pagos son hechos por compañías estadounidenses que previamente han 
realizado acuerdos con compañías locales por los usos de la red de interconexión. Esto permite que no sólo se obtengan ingresos por las Ilamadas salientes, sino también por las entrantes.

Tal escenario ha facilitado la aplicación de un impuesto, ya que en junio de 2008, el gobierno de El Salvador decretó un impuesto de \$0.04 por minuto de Ilamada entrante desde los Estados Unidos, con el cual espera percibir $\$ 110$ millones en el primer año (La Prensa Gráfica, 2008: en línea), ya que para el 2007 el número de minutos de Ilamadas entrantes fue aproximadamente de 2,768 millones, creciendo en el último quinquenio $182 \%$.

El crecimiento del sector y su importancia dentro del PIB se puede observar en la tabla II-1, donde se puede ver un crecimiento desde un $2 \%$ en la década de los 90 's a un $4 \%$ en el 2007.

\section{Tabla II-1 Crecimiento del sector comunicaciones y su relación con respecto al PIB}

\begin{tabular}{|cccc}
\hline AÑOS & $\begin{array}{c}\text { MONTOS EN MILLONES } \\
\text { USD }\end{array}$ & $\begin{array}{c}\text { \% DE CRECIMIENTO } \\
\text { ANUAL }\end{array}$ & \% RESPECTO AL PIB \\
\hline $\mathbf{1 9 9 0}$ & 97.4 & & $2 \%$ \\
$\mathbf{1 9 9 1}$ & 97.8 & $0 \%$ & $2 \%$ \\
\hline $\mathbf{1 9 9 2}$ & 106.7 & $9 \%$ & $2 \%$ \\
$\mathbf{1 9 9 3}$ & 109.1 & $2 \%$ & $2 \%$ \\
$\mathbf{1 9 9 4}$ & 119.4 & $9 \%$ & $2 \%$ \\
$\mathbf{1 9 9 5}$ & 114.1 & $-4 \%$ & $2 \%$ \\
$\mathbf{1 9 9 6}$ & 121.7 & $7 \%$ & $2 \%$ \\
\hline $\mathbf{1 9 9 7}$ & 136.0 & $12 \%$ & $2 \%$ \\
$\mathbf{1 9 9 8}$ & 139.3 & $2 \%$ & $2 \%$ \\
\hline $\mathbf{1 9 9 9}$ & 178.8 & $28 \%$ & $2 \%$ \\
$\mathbf{2 0 0 0}$ & 200.3 & $12 \%$ & $3 \%$ \\
\hline $\mathbf{2 0 0 1}$ & 223.3 & $11 \%$ & $3 \%$ \\
\hline $\mathbf{2 0 0 2}$ & 231.8 & $4 \%$ & $3 \%$ \\
$\mathbf{2 0 0 3}$ & 244.8 & $6 \%$ & $3 \%$ \\
\hline $\mathbf{2 0 0 4}$ & 259.4 & $6 \%$ & $3 \%$ \\
\hline $\mathbf{2 0 0 5}$ & 292.0 & $13 \%$ & $3 \%$ \\
\hline $\mathbf{2 0 0 6}$ & 316.8 & $8 \%$ & $4 \%$ \\
$\mathbf{2 0 0 7}$ & 348.4 & $10 \%$ & $4 \%$ \\
\hline
\end{tabular}

Fuente: Elaboración propia en base a datos del BCR en línea www.bcr.gob.sv. Montos y PIB a precios constantes

Otro sector con gran dinamismo debido al auge de las migraciones es el transporte aéreo, ya que los migrantes, una vez legalizada su residencia en el exterior, se transportan en mayor medida por esta vía, asimismo sus familiares. 
Tabla II-2. Tráfico aéreo de pasajeros: 1990 - 2007

\begin{tabular}{|ccc|}
\hline AÑOS & TRÁFICO INTERNACIONAL & VARIACIÓN ANUAL \\
\hline 1990 & $504,793.0$ & $0 \%$ \\
\hline 1991 & $537,591.0$ & $6 \%$ \\
\hline 1992 & $725,336.0$ & $35 \%$ \\
\hline 1993 & $781,464.0$ & $8 \%$ \\
\hline 1994 & $831,286.0$ & $6 \%$ \\
\hline 1995 & $923,383.0$ & $11 \%$ \\
\hline 1996 & $872,685.0$ & $-5 \%$ \\
\hline 1997 & $908,616.0$ & $4 \%$ \\
\hline 1998 & $1,154,028.0$ & $27 \%$ \\
\hline 1999 & $1,259,951.0$ & $9 \%$ \\
\hline 2000 & $1,256,282.0$ & $0 \%$ \\
\hline 2001 & $1,294,866.0$ & $3 \%$ \\
\hline 2002 & $1,344,889.0$ & $4 \%$ \\
\hline 2003 & $1,312,984.0$ & $-2 \%$ \\
\hline 2004 & $1,459,653.0$ & $11 \%$ \\
\hline 2005 & $1,540,925.0$ & $6 \%$ \\
\hline 2006 & $1,563,140.0$ & $1 \%$ \\
\hline 2007 & $1,551,102.0$ & $-1 \%$ \\
\hline $1990 / 2007$ & & $207 \%$ \\
\hline
\end{tabular}

Fuente: Elaboración propia en base a datos de BCR en línea www.bcr.gob.sv Acumulado a diciembre de cada año de entradas y salidas de pasajeros por terminal aérea.

Se observa en la tabla que el crecimiento del tráfico aéreo de pasajeros en los últimos 17 años ha sido del $207 \%{ }^{11}$, con un promedio de crecimiento anual del $7 \%$. Dada esta tendencia creciente de personas que viajan desde y hacia los Estados Unidos y Canadá, varias compañías aéreas han desarrollado estrategias comerciales con las que buscan mejorar su posicionamiento y participación en el mercado. Esta situación ha permitido mayor competencia entre las empresas que se dedican a este sector, mayores inversiones al crear nuevas rutas e incrementando los vuelos El Salvador - Estados Unidos.

El siguiente rubro es el mercado de transferencias. Este mercado se refiere al traslado de dinero $\mathrm{u}$ otros bienes entre los migrantes y sus familiares. Los proveedores de este servicio han crecido, entre ellos, las empresas dedicadas al envío de correspondencia, los bancos que cuentan con agencias en el exterior, cajas de ahorro y crédito, encomenderos, etc. 
El crecimiento de este sector está ligado al incremento de la migración, y el componente de mayor dinamismo es probablemente la transferencia de remesas. Para refle- jar la importancia de este mercado, se aplicará un costo promedio de remisión de remesas de $4.45 \%{ }^{12}$, dando como resultado la Tabla II-3.

Tabla II-3 Ingresos por transferencia de remesas y su relación respecto a PIB: 1997 - 2007

\begin{tabular}{cccc}
\hline AÑOS & REMESAS & $\begin{array}{c}\text { INGRESOS POR } \\
\text { TRANSFERENCIAS DE } \\
\text { REMESAS MILL USD }\end{array}$ & $\begin{array}{c}\text { \% RESPECTO } \\
\text { AL PIB }\end{array}$ \\
\hline 1997 & $1,199.5$ & 53.4 & $0.5 \%$ \\
\hline 1998 & $1,338.3$ & 59.6 & $0.5 \%$ \\
\hline 1999 & $1,373.8$ & 61.1 & $0.5 \%$ \\
\hline 2000 & $1,750.7$ & 77.9 & $0.6 \%$ \\
\hline 2001 & $1,910.5$ & 85.0 & $0.6 \%$ \\
\hline 2002 & $1,935.2$ & 86.1 & $0.6 \%$ \\
\hline 2003 & $2,105.3$ & 93.7 & $0.6 \%$ \\
\hline 2004 & $2,547.6$ & 113.4 & $0.7 \%$ \\
\hline 2005 & $3,017.2$ & 134.3 & $0.8 \%$ \\
\hline 2007 & $3,470.9$ & 154.5 & $0.8 \%$ \\
\hline
\end{tabular}

Fuente: Elaboración propia en base a datos del BCR en línea www.bcr.gob.sv Montos, remesas y PIB a precios corrientes

Datos estimados por transferencia bajo entidades formales, ya que no existen datos reales del país al respecto y no se toma en cuenta los ingresos por Encomenderos.

En el cuadro se puede observar como la importancia con respecto al PIB ha pasado de un $0.5 \%$ en 1997 a un $0.8 \%$ para el último año.

Otro sector en auge es el Turismo, el cual ha crecido enormemente gracias al turismo étnico. Para tener una idea del impacto, para el 2007 los ingresos por turismo ascendieron aproximadamente a 835 millones USD (Ver tabla anexo B2), representando un crecimiento de 1,935\% en los últimos doce años.

En El Salvador, más del 40\% de llegadas al país son de salvadoreños, lo que ha generado una gran demanda de nuevos bienes y servicios que muchas empresas turísticas se han tomado la tarea de satisfacer ofreciendo paquetes turísticos, viajes y bienes raíces en regiones costeras (Orozco, Manuel 2005) 
Tabla II-4. Crecimiento del turismo étnico y su relación con respecto al PIB: 1995 - 2007

\begin{tabular}{ccccc}
\hline AÑO & $\begin{array}{c}\text { MONTOS EN } \\
\text { MILLONES USD }\end{array}$ & $\begin{array}{c}\text { MONTOS POR } \\
\text { TURISMO ÉTNICO }\end{array}$ & $\begin{array}{c}\text { \% DE CRECIMIENTO } \\
\text { ANUAL POR TURISMO } \\
\text { ÉTNICO }\end{array}$ & $\begin{array}{c}\% \text { RESPECTO } \\
\text { AL PIB }\end{array}$ \\
\hline 1995 & 40.9 & 16.36 & & $1 \%$ \\
\hline 1996 & 44.2 & 17.68 & $8 \%$ & $1 \%$ \\
\hline 1997 & 75.6 & 30.24 & $71 \%$ & $2 \%$ \\
\hline 1998 & 126.7 & 50.68 & $68 \%$ & $3 \%$ \\
\hline 1999 & 212.4 & 84.96 & $68 \%$ & $4 \%$ \\
\hline 2000 & 215.7 & 86.28 & $2 \%$ & $4 \%$ \\
\hline 2001 & 199.4 & 79.76 & $-8 \%$ & $4 \%$ \\
\hline 2002 & 289.9 & 115.96 & $45 \%$ & $5 \%$ \\
\hline 2003 & 316.8 & 126.72 & $9 \%$ & $6 \%$ \\
\hline 2004 & 353.4 & 141.36 & $12 \%$ & $6 \%$ \\
\hline 2005 & 542.1 & 216.84 & $53 \%$ & $9 \%$ \\
\hline 2006 & 788.7 & 315.48 & $45 \%$ & $12 \%$ \\
\hline 2007 & 832.5 & 333 & $6 \%$ & $12 \%$ \\
\hline
\end{tabular}

Fuente: Elaboración propia en base a datos de BCR en línea www.bcr.gob.sv y de CORSATUR en línea www.corsatur.gob.sv. multiplicados por $40 \%{ }^{13}$ ya que no se encontraron datos desagregados que muestren el crecimiento de este sector por los migrantes salvadoreños.

Montos y PIB a precios corrientes

Los datos estimados muestran un crecimiento medio anual en este sector de $32 \%$ generado por el turismo étnico en los últimos 13 años, pasando de representar un $1 \%$ dentro del PIB en el 95, a un 12\% en el 2007 aproximadamente.

Un quinto rubro favorecido es el mercado de consumo de productos nostálgicos, que experimenta en la actualidad gran dinamismo como consecuencia principal de la demanda de productos de consumo, que la población salvadoreña que reside en el exterior realiza debido a los hábitos que adquirieron en su país de origen relacionados con su cultura.
El consumo de productos étnicos incluye tamales, cervezas, chiles, frijoles rojos, loroco, horchata, pacaya entre otros. De acuerdo al Programa de Remesas del Centro de Estudios Monetarios Latinoamericanos, los salvadoreños residentes en EUA compraron más de $\$ 40$ millones en productos autóctonos en el 2004.

En el sector vivienda, de acuerdo al artículo "De moda las de $\$ 50,000 "$, del periódico La Prensa Gráfica, edición del 15 de mayo de 2007, menciona que los emigrantes han intensificado este sector de manera importante ya que la banca privada y el Fondo Social para la 
Vivienda (FSV) manejan que casi un $40 \%$ de sus clientes, desde 2004 a la fecha, son salvadoreños que residen en Estados Unidos y otros países. "Un segmento que hay que destacar por tomar cada vez mayor relevancia en el mercado de compra de vivienda es el del salvadoreño en el exterior", mencionó el presidente ejecutivo de Scotiabank El Salvador, Sergio Concha. De acuerdo a este mismo artículo, desde 2004, más de 3,000 créditos han sido adquiridos por salvadoreños que viven en Norteamérica, con un promedio de $\$ 30,000$ otorgados por los bancos, y $\$ 7,200$ por el Fondo. En total, estas personas han invertido en casas más de $\$ 93.7$ millones en ese mismo lapso de tiempo.

En la Tabla II-5 se puede observar una aproximación del crecimiento que ha tenido este sector gracias a los migrantes salvadoreños que han comprado viviendas en el país. De acuerdo a los datos estimados, el crecimiento medio anual de este sector impulsado por los migrantes ha sido aproximadamente de $8 \%$, y un crecimiento total de $314 \%$ en los últimos 16 años.

\section{Tabla II-5. Crecimiento del sector vivienda y su relación con respecto al} PIB: $1992-2007$

\begin{tabular}{lcccc}
\hline AÑO & $\begin{array}{c}\text { MONTOS TOTALES } \\
\text { EN MILLONES USD }\end{array}$ & $\begin{array}{c}\text { MONTOS POR } \\
\text { COMPRA DE } \\
\text { MIGRANTES }\end{array}$ & $\begin{array}{c}\text { \% DE CRECIMIENTO } \\
\text { ANUAL POR } \\
\text { COMPRAS DE } \\
\text { MIGRANTES }\end{array}$ & $\begin{array}{c}\text { \% RESPECTO AL } \\
\text { PIB }\end{array}$ \\
\hline 1992 & 262.8 & 105.12 & & $9 \%$ \\
\hline 1993 & 303.7 & 121.48 & $16 \%$ & $10 \%$ \\
\hline 1994 & 374.2 & 149.68 & $23 \%$ & $10 \%$ \\
\hline 1995 & 416.3 & 166.52 & $11 \%$ & $10 \%$ \\
\hline 1996 & 443.9 & 177.56 & $7 \%$ & $10 \%$ \\
\hline 1997 & 473.7 & 189.48 & $7 \%$ & $10 \%$ \\
\hline 1998 & 533.1 & 213.24 & $13 \%$ & $11 \%$ \\
\hline 1999 & 533.3 & 213.32 & $0 \%$ & $11 \%$ \\
\hline 2000 & 572.1 & 228.84 & $7 \%$ & $11 \%$ \\
\hline 2001 & 646.7 & 258.68 & $13 \%$ & $12 \%$ \\
\hline 2002 & 688.6 & 275.44 & $6 \%$ & $13 \%$ \\
\hline 2003 & 705.6 & 282.24 & $2 \%$ & $12 \%$ \\
\hline 2004 & 657.8 & 263.12 & $-7 \%$ & $11 \%$ \\
\hline 2005 & 710.7 & 284.28 & $8 \%$ & $11 \%$ \\
\hline 2006 & 778.8 & 311.52 & $10 \%$ & $12 \%$ \\
\hline 2007 & 824.6 & 329.84 & $6 \%$ & $12 \%$ \\
\hline
\end{tabular}

Fuente: Elaboración propia en base a datos del BCR en línea www.bcr.gob.sv

Del sector construcción multiplicados por $40 \%{ }^{14}$ ya que no se encontraron datos desagregados que muestren el crecimiento de este sector por los migrantes salvadoreños.

Montos y PIB a precios corrientes. 


\subsection{Efectos microeconómicos}

Las remesas son un factor de gran peso en la supervivencia de millones de familias y en la salud económica de muchos países. A diferencia de la ayuda exterior, las remesas logran llegar directamente a las familias que inclusive pueden encontrarse en lugares donde la ayuda externa es difícil de acceder.

En El Salvador los hogares receptores de remesas se incrementaron 36\% en el período 2001-2006, alcanzando para este último año un total de 417,331 hogares receptores, equivalente aproximadamente al $24 \%$ del total de hogares del país (Gráfico II-5), lo cual implica que probablemente todos ellos tenían al menos un familiar residiendo en el extranjero.

En el transcurso de los años, las remesas se han concentrado en las zonas urbanas, representando hace dos años, aproximadamente, el $61 \%$ del total de las mismas contra un $39 \%$ en el área rural (Ver Tabla II-6.).

\section{Gráfico II-5 Número de hogares receptores de remesas y su relación con respecto al País: 1998 - 2006}

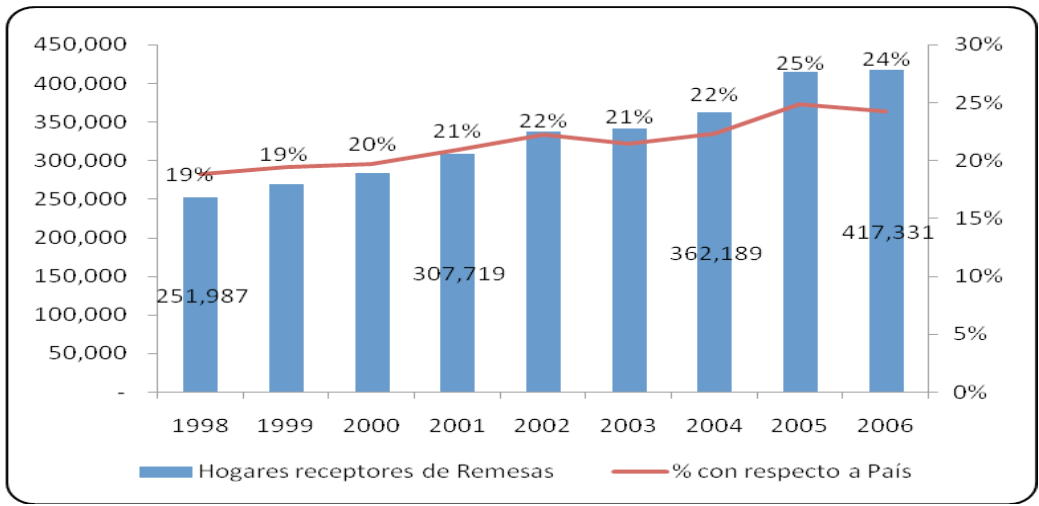

Fuente: Elaboración propia en base a datos de la EHPM en línea www.digestyc.gob.sv 


\begin{tabular}{|c|c|c|c|c|c|}
\hline Años & Total & Urbano & $\%$ Urbano & Rural & $\%$ Rural \\
\hline 1998 & 251,987 & 156,826 & $62 \%$ & 95,161 & $38 \%$ \\
\hline 1999 & 268,780 & 166,891 & $62 \%$ & 101,889 & $38 \%$ \\
\hline 2000 & 283,650 & 173,824 & $61 \%$ & 109,826 & $39 \%$ \\
\hline 2001 & 307,719 & 187,568 & $61 \%$ & 120,151 & $39 \%$ \\
\hline 2002 & 337,580 & 205,380 & $61 \%$ & 132,200 & $39 \%$ \\
\hline 2003 & 340,964 & 207,923 & $61 \%$ & 133,041 & $39 \%$ \\
\hline 2004 & 362,189 & 232,171 & $64 \%$ & 130,018 & $36 \%$ \\
\hline 2005 & 414,871 & 257,682 & $62 \%$ & 157,189 & $38 \%$ \\
\hline 2006 & 417,331 & 254,897 & $61 \%$ & 162,434 & $39 \%$ \\
\hline
\end{tabular}

Fuente: Elaboración propia en base a datos de la EHPM en línea www.digestyc.gob.sv

A nivel nacional la recepción de remesas ha favorecido considerablemente el ingreso familiar, representando en el 2006 un promedio del $32 \%$ dentro de este para el área urbana y aproximadamente un 55\% para el área rural; este porcentaje se ha convertido en parte importante para la cobertura de sus necesidades, destinando estos ingresos a: Consumo, vivienda, Co- mercio, salud, educación, ahorro, entre otros. El gráfico II-6 muestra la relación porcentual que tienen las remesas en el ingreso de los hogares por áreas y la variación de este porcentaje año con año. Aunque el porcentaje de hogares urbanos que recibe remesas es mayor, la proporción del ingreso que cubren las remesas es menor ya que son más importantes en el área rural.

\section{Gráfico II-6 Relación de participación de las remesas en el ingreso familiar por área: 1998 - 2006}

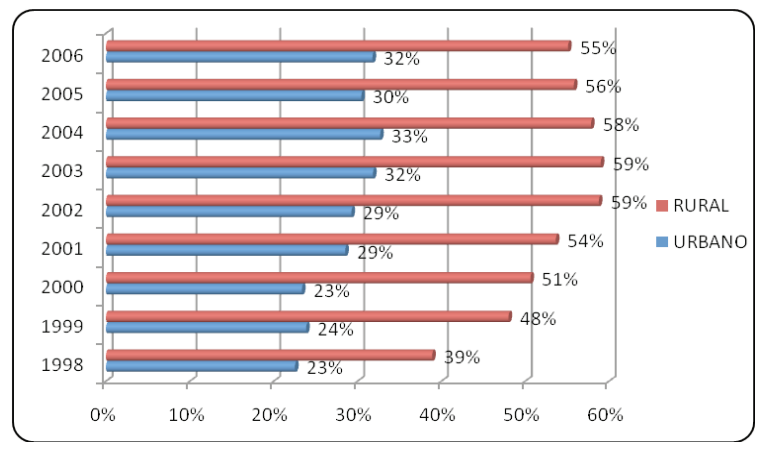

Fuente: Elaboración propia en base a datos de la EHPM en línea www.digestyc.gob.sv 
Según PRISMA (2006), los hogares donde se ha presentado un mayor aumento porcentual de envío de remesas ha sido en aquellos con una economía campesina tradicional y ganadera. Lo que ha desembocado en un resquebrajamiento total de la economía rural tradicional, ya que los hogares que perciben remesas optan por trasladar a sus familias donde se encuentran las oportunidades del país.

Por lo tanto, la dinámica migratoria está ensanchando la brecha territorial y social del campo, pues lo que hace 25 años era homogéneo, hoy presenta una clara diferencia entre los hogares con y sin remesas.

Según datos de PRISMA, el peso de las remesas dentro del sustento de los hogares rurales con migrantes dependerá del área geográfica y de la historia migratoria en esa zona, es decir, en las áreas en donde se inició el proceso de migración décadas atrás, es en donde representan la principal fuente de ingreso. Por otro lado, en las localidades rurales en donde el fenómeno migratorio inició recientemente el $50 \%$ de los hogares aún depende del agro, tanto para autoconsumo como para venta, pero las remesas representan la segunda fuente de sustento para aproximadamente el $25 \%$ de estas familias.
En este ámbito, la emigración tiene doble efecto en los países. Por un lado disminuye las presiones sociales sobre el empleo y los servicios sociales. Por el otro, la emigración, junto con las remesas, representan un alivio a la pobreza. Para la persona que migra significa la oportunidad de aumentar sus ingresos y para la familia que queda en el país de origen, un ingreso para suplir las necesidades de alimentación, salud, educación, entre las principales, que de otra forma no podrían ser satisfechas.

A un nivel un tanto general, los migrantes se han dedicado también a ayudar a sus comunidades de origen, aportando significativas sumas destinadas a producir obras que permiten mejorar el estilo de vida de tales localidades. Por ejemplo: un proyecto de cultivo, procesamiento y comercialización de productos agrícolas en San Pedro Masahuat, un centro de cómputo en la comunidad El Piche, aulas y laboratorio de inglés en San Vicente, entre otros. Este tipo de obras son más enfocadas a lo social, un ámbito que el gobierno tiende a dejar de lado, ocupándose mayoritariamente a infraestructura que estimula el desarrollo económico de acuerdo al modelo en vigencia. 


\section{Efectos de las migraciones y la funcionalidad con el modelo económico estructural}

Las remesas han venido a disminuir la pobreza al interior del país. De acuerdo a los estándares internacionales, la pobreza relativa se presenta cuando los ingresos de una familia le permiten obtener la canasta básica alimentaria mas no le permiten cubrir esta canasta multiplicada por dos. La pobreza extrema se presenta cuando el ingreso no logra cubrir las necesidades de alimentación básicas.

Sin embargo debe tomarse en cuenta que las remesas contribuyen a contrarrestar en mayor medida la pobreza en el área rural, dado que existe, sólo para el 2006, un mayor porcentaje de hogares en situación de pobreza (extrema $12.2 \%$, relativa $23.6 \%$ ), frente al área urbana (extrema $8 \%$, relativa $19.8 \%$ ).
De acuerdo a los datos que se presentaron anteriormente, los ingresos de las familias salvadoreñas sin tener en cuenta las remesas, ocasionarían que muchas de ellas se vieran en una situación de pobreza, en la tabla II-7 se muestra que a nivel general para 2006, los ingresos de los hogares con y sin remesas tanto en el área urbana como en la rural, logran cubrir la canasta básica en su totalidad. En cambio, si se duplica el precio de la canasta básica y sustraemos las remesas de los ingresos, estos en el área rural no lograrían cubrir el 100\%, llegando a representar la mitad de este precio, poniendo a muchas familias en situación de pobreza relativa.

Tabla II-7 Canasta básica y su relación al ingreso con y sin remesas: $2001-2006$

\begin{tabular}{cccccc}
\hline \multicolumn{7}{c}{ RURAL } \\
AÑOS & $\begin{array}{c}\text { PRECIO } \\
\text { CANASTA } \\
\text { BASICA } \\
\text { (USD) }\end{array}$ & $\begin{array}{c}\text { INGRESO } \\
\text { CON } \\
\text { REMESAS } \\
\text { (USD) }\end{array}$ & $\begin{array}{c}\text { INGRSO } \\
\text { COMESAS } \\
\text { VRS. } \\
\text { CANASTA } \\
\text { BASICA }\end{array}$ & $\begin{array}{c}\text { INGRESO } \\
\text { IN REMESAS } \\
\text { (USD) }\end{array}$ & $\begin{array}{c}\text { \% INGRESO } \\
\text { SIN REMESAS } \\
\text { VRS. } \\
\text { CANASTA } \\
\text { BASICA }\end{array}$ \\
\hline 2001 & 96.78 & 232.98 & 241 & 107.96 & 112 \\
\hline 2002 & 93.29 & 232.56 & 249 & 95.83 & 103 \\
\hline 2003 & 89.87 & 235.99 & 263 & 96.71 & 108 \\
\hline 2004 & 96.73 & 257.11 & 266 & 108.35 & 112 \\
\hline 2005 & 100.61 & 279.42 & 278 & 123.47 & 123 \\
\hline
\end{tabular}




\begin{tabular}{cccccc}
\hline \multicolumn{7}{c}{ RURAL } \\
AÑOS & $\begin{array}{c}\text { PRECIO } \\
\text { CANASTA } \\
\text { BASICA X2 } \\
\text { (USD) }\end{array}$ & $\begin{array}{c}\text { INGRESO } \\
\text { CON } \\
\text { REMESAS } \\
\text { (USD) }\end{array}$ & $\begin{array}{c}\text { CON } \\
\text { REMESAS } \\
\text { VRS. } \\
\text { CANASTA } \\
\text { BASICA X2 }\end{array}$ & $\begin{array}{c}\text { IN } \\
\text { INGRESO } \\
\text { (USD) }\end{array}$ & $\begin{array}{c}\text { INGRESO } \\
\text { CON } \\
\text { REMESAS } \\
\text { VRS. } \\
\text { CANASTA } \\
\text { BASICA X2 }\end{array}$ \\
\hline 2001 & 193.56 & 232.98 & 120 & 107.96 & 56 \\
\hline 2002 & 186.58 & 232.56 & 125 & 95.83 & 51 \\
\hline 2003 & 179.74 & 235.99 & 131 & 96.71 & 54 \\
\hline 2004 & 193.46 & 257.11 & 133 & 108.35 & 56 \\
\hline 2005 & 201.22 & 279.42 & 139 & 123.47 & 61 \\
\hline 2006 & 197.84 & 284.21 & 144 & 127.55 & 64 \\
\hline
\end{tabular}

\begin{tabular}{|c|c|c|c|c|c|}
\hline \multicolumn{6}{|c|}{ URBANO } \\
\hline AÑOS & $\begin{array}{c}\text { PRECIO } \\
\text { CANASTA } \\
\text { BASICA } \\
\text { (USD) }\end{array}$ & $\begin{array}{l}\text { INGRESO } \\
\text { CON } \\
\text { REMESAS } \\
\text { (USD) }\end{array}$ & $\begin{array}{l}\% \text { INGRESO } \\
\text { CON } \\
\text { REMESAS } \\
\text { VRS. } \\
\text { CANASTA } \\
\text { BASICA } \\
\end{array}$ & $\begin{array}{l}\text { INGRESO } \\
\text { SIN REMESAS } \\
\text { (USD) }\end{array}$ & $\begin{array}{c}\% \text { INGRESO } \\
\text { SIN REMESAS } \\
\text { VRS. } \\
\text { CANASTA } \\
\text { BASICA }\end{array}$ \\
\hline 2001 & 127.97 & 531.87 & 416 & 380.09 & 297 \\
\hline 2002 & 127.04 & 545.16 & 429 & 385.53 & 303 \\
\hline 2003 & 126.47 & 506.29 & 400 & 345.02 & 273 \\
\hline 2004 & 129.57 & 512.54 & 396 & 344.93 & 266 \\
\hline 2005 & 135.53 & 525.89 & 388 & 365.69 & 270 \\
\hline 2006 & 137.78 & 535.71 & 389 & 365.37 & 265 \\
\hline
\end{tabular}

\begin{tabular}{cccccc}
\hline \multicolumn{7}{c}{ URBANO } \\
\hline AÑOS & $\begin{array}{c}\text { PRECIO } \\
\text { CANASTA } \\
\text { BASICA X2 } \\
\text { (USD) }\end{array}$ & $\begin{array}{c}\text { INGRESO } \\
\text { CON } \\
\text { REMESAS } \\
\text { (USD) } \\
\text { CON } \\
\text { REMESAS } \\
\text { VRS. } \\
\text { CANASTA } \\
\text { BASICA X2 }\end{array}$ & $\begin{array}{c}\text { SIN REMESAS } \\
\text { INSD) }\end{array}$ & $\begin{array}{c}\text { \% INGRESO } \\
\text { CON } \\
\text { REMAS } \\
\text { VRS. } \\
\text { CANASTA } \\
\text { BASICA X2 }\end{array}$ \\
\hline 2001 & 255.94 & 531.87 & 208 & 380.09 & 149 \\
\hline 2002 & 254.08 & 545.16 & 215 & 385.53 & 152 \\
\hline 2003 & 252.94 & 506.29 & 200 & 345.02 & 136 \\
\hline 2004 & 259.14 & 512.54 & 198 & 344.93 & 133 \\
\hline 2005 & 271.06 & 525.89 & 194 & 365.69 & 135 \\
\hline 2006 & 275.56 & 535.71 & 194 & 365.37 & 133 \\
\hline
\end{tabular}

Fuente: Elaboración propia en base a datos de la EHPM en línea www.digestyc.gob.sv 
Los datos indican que las familias rurales, sin las remesas, no lograrían accesar a la canasta ampliada dentro de la economía local, brindándoles una condición precaria generalizada que ha perdurado a través de los años, haciendo casi evidente que el problema es de índole estructural.

A nivel macroeconómico, en la economía salvadoreña hubo cambios en la producción a lo largo de los últimos 17 años. Parte de estos cambios se han debido al constante flujo de remesas. En la tabla II-8 se encuentran tres promedios del Índice de Variación de Actividad Económica (IVAE) de los diversos sectores de la economía, y de acuerdo a estos resultados, el dinamismo del sector tradicional ha sido mínimo, mientras que los sectores que más dinamismo han experimentado han sido los de servicios, tales como servicios básicos, transporte, instituciones financieras, bienes inmuebles y servicios a empresas.

\section{Tabla II-8 Cambios en el consumo Índice de Volumen de Actividad Económica, IVAE}

\begin{tabular}{lccccccccccc}
\hline Promedios & S1 & S2 & S3 & S4 & S5 & S6 & S7 & S8 & S9 & S10 & S11 \\
\hline Desde 1991 & 1.4 & 4.5 & 5.4 & 5.2 & 3.7 & 4.5 & 7.8 & 10.9 & 3.7 & 2.7 & 1.3 \\
Desde 2000 & 0.1 & 3.1 & 1.6 & 4.4 & 0.9 & 1.8 & 5.3 & 5.2 & 3.6 & 2.2 & 1.9 \\
Desde 2002 & 2.9 & 0.0 & 0.7 & 4.3 & -2.4 & 2.4 & 7.9 & 5.9 & 4.5 & 3.1 & 3.1
\end{tabular}

Fuente: Elaboración propia en base a datos del BCR en línea www.bcr.gob.sv

S1: Agrícultura, Caza, Pesca y Silvicultura; S2: Minas y Canteras; S3: Industria Manufacturera; S4: Electricidad, Gas y Agua; S5: Construcción; S6: Comercio, Restaurantes y Hoteles; S7: Transporte, Almacenamiento y Comunicaciones; S8: Bancos, Seguros y Otras Instituciones Financieras; S9: Bienes Inmuebles y Servicios a Empresas; S10: Ss. Com., Soc y Per.; S11: Servicios del Gob

Aparte de los cambios en el consumo, si el país no contara con las remesas, la economía no tendría las divisas suficientes para cubrir el déficit comercial generado por la falta de exportaciones como consecuencia de la poca producción interna del país (Gráfico II-7), no permitiendo cubrir la demanda de importaciones que incluye bienes de consumo, bienes de capital, e intermedios, lo que desembocaría en mayor grado de desempleo y crisis económica. 
Gráfico II-7: Déficit comercial vrs. remesas: 2000 - 2007

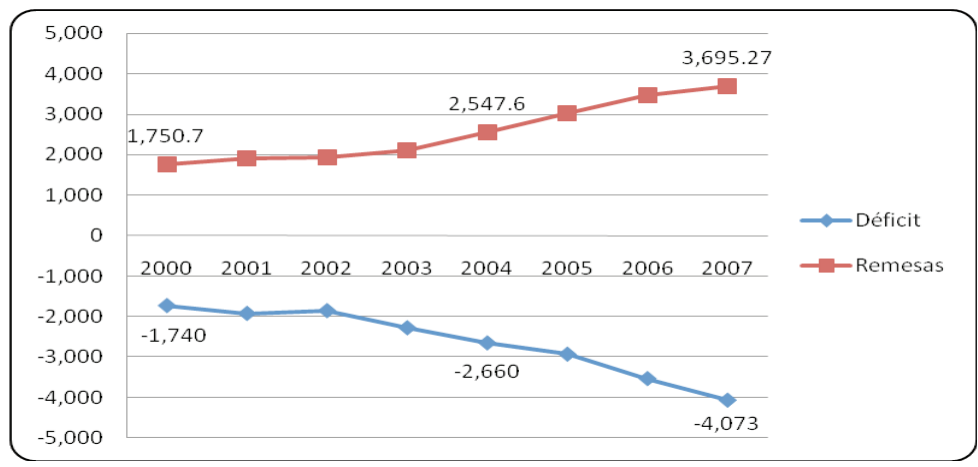

Fuente: Elaboración propia en base a datos del BCR en línea www.bcr.gob.sv Millones de dólares

Esta situación pone en evidencia que las políticas estatales no han sido encaminadas fuertemente a reducir los problemas del empleo, que abarcan desempleo abierto y subempleo, lo que viene a reflejar que El Salvador necesita expulsar mano de obra y a la vez mantener el vínculo con los hermanos lejanos a fin de hacer sostenible la economía salvadoreña.

Bajo este contexto, se vuelve necesario elaborar un modelo econométrico que permita visualizar la principal causa de origen estructural que impulsa las migraciones en el país, tema que será abordado en el siguiente capítulo.

\section{Modelo de cobertura de las necesidades promedio y emigración}

\subsection{Presentación del modelo}

La emigración, como se entiende en los países subdesarrollados, es una alternativa para muchas familias que se ven enfrentadas a diversas situaciones en sus países de origen, situaciones que pueden tener una o varias causas en común y es precisamente esas causas las que se tratarán de determinar con el modelo econométrico a desarrollar en este capítulo.

El modelo está sustentado en que en El Salvador la migración es causada principalmente por la falta de cobertura de las necesidades promedio de la fuerza de trabajo.

La cobertura del valor de la fuerza de trabajo concierne a la 


\section{을 satisfacción de las necesidades pro- medio que las familias requieren para sostenerse y reproducirse en condiciones dignas y estables, es decir en condiciones socialmente aceptables, tales como una ali- mentación completa y balanceada, vivienda, vestuario, salud, educa- ción, servicios básicos, transporte, entre otros.}

Las necesidades promedio se refiere, en especial, a las necesidades de tipo material que poseen las familias a fin de lograr sostenerse y reproducirse en condiciones socialmente aceptables. Estas se traducen en una canasta que cubre las necesidades de una alimentación completa y balanceada, vivienda, vestuario, salud, educación, servicios básicos, transporte, entre otros. En El Salvador, estas necesidades se reúnen en gran parte dentro de la Ilamada canasta de mercado, la cual será tomada como referencia a lo largo de esta investigación.

La canasta de mercado es definida, por la DIGESTYC, como el conjunto de bienes y servicios que en promedio sirven para satisfacer las necesidades básicas de una familia típica salvadoreña y contiene rubros como: salud, alimentación, vivienda, vestuario, educación, transporte y recreación. Es por esta razón que a lo largo de este capítulo se tomará el precio de la canasta de mercado como medida del costo de las necesidades promedio de una familia, ya que es el dato que más se aproxima a satisfacerlas y sobre el que existe información a lo largo de los últimos años.

El modelo sobre "Cobertura de las Necesidades Promedio" esencialmente pretende verificar si la canasta de mercado es satisfecha o no por los ingresos que actualmente las familias perciben, y en qué medida este grado de cobertura se convierte en el principal impulsador de la migración externa en El Salvador, al no permitir la reproducción de la fuerza de trabajo.

En este contexto, el modelo, además de tomar en cuenta la cobertura del valor de la fuerza de trabajo, toma en cuenta otros elementos relacionados como el desempleo y desempleo equivalente, el grado de pobreza o no pobreza de las familias y la capacidad y calidad de inserción de las mismas al mercado laboral local.

Se espera demostrar que el incremento del desempleo y el desempleo equivalente, así como el aumento en la falta de cobertura del valor de la fuerza de trabajo son los promotores de la migración en el país.

Asimismo se espera que los sectores con un grado de extrema pobreza o un grado de extrema riqueza no se traduzcan en migrantes, ya que se toma como supuesto que las familias en extrema pobreza no cuentan con los recursos 
necesarios para poder migrar ni a través de medios ilegales (como los "coyotes"); mientras que las familias en extrema riqueza cuentan con los recursos necesarios dentro del país para sostenerse en condiciones dignas y estables, por lo que no presentan la necesidad de migrar. Por otro lado se espera que los sectores migrantes sean los que se encuentran en situación de pobreza relativa y en no pobreza.

Además se espera que la migración dependa de un bajo grado de capacidad y calidad de inserción de las familias al mercado laboral. En la capacidad de inserción, una familia en donde sus miembros pertenecientes a la PEA no posean en promedio una edad y un nivel de estudios valorados en el mercado de trabajo, sus oportunidades de empleo serán bajas, teniendo que recurrir a la búsqueda de empleo en economías extranjeras. En cuanto a la calidad de inserción, se espera que en una familia donde sus miembros ocupados posean empleo inestable y que no les brinde protección social y buenas condiciones laborales, sean propensos a buscar mejores empleos fuera del país, a fin de ver garantizado el sostenimiento y reproducción de su familia.

El desempleo será medido por el índice de desempleo abierto y de desempleo equivalente existente dentro de cada familia. El grado de cobertura del valor de la fuerza de trabajo será medido por la relación entre el ingreso per cápita sin remesas por familia y el precio de la canasta de mercado per cápita por familia del 2006.

El grado de pobreza se medirá en base al precio de la canasta básica alimentaria de acuerdo a la línea oficial de pobreza. Una familia en situación de pobreza extrema será aquella que perciba ingresos mensuales menores al precio de la canasta básica mensual. Una familia en situación de pobreza relativa será aquella que perciba ingresos mensuales por encima de la canasta básica, pero menores a la misma canasta multiplicada por dos.

La no pobreza será medida en base al precio de la canasta ampliada. Una familia será no pobre en tanto reciba ingresos por encima del precio de la canasta ampliada per cápita para esa familia.

El grado de capacidad al mercado laboral local, será medido en base al grado de escolaridad y edad que posean en promedio los miembros de la unidad familiar que formen parte de la PEA. La calidad de inserción se medirá por el tipo de empleo que posean en promedio los ocupados de la familia.

Finalmente, la variable dependiente, el grado de migración, será medido a través de si la familia percibe un ingreso significativo en concepto de remesas con respecto 
al ingreso familiar. Con esto se supondrá que la familia tiene al le ayuda económicamente con el menos un familiar en el exterior que

\section{Presentación de resultados del modelo}

En esta sección se pretende demostrar si la decisión de emigrar como familia depende de la cobertura del valor de la fuerza de trabajo, desempleo, desempleo equivalente, pobreza extrema y la no pobreza.

Para explicarlo se construyó el siguiente modelo de regresión logística ${ }^{15}$ :

$\operatorname{Ln}(p / q)=\beta_{1}$ Cobertura $+\beta_{2}$ Desempleo $+\beta_{3}$ Desempleo Equivalente +

$\beta_{4}$ Pobreza Extrema $+\beta_{5}$ No Pobreza $+\beta_{6}$ Riqueza

Donde:

$\operatorname{Ln}(p / q)=$ Es la probabilidad que suceda $P$ dado $Q$.

Los resultados del modelo se muestran a continuación:

\section{Tabla III-7. Resultados del Modelo}

\begin{tabular}{|c|c|c|c|c|c|c|c|c|c|}
\hline \multicolumn{10}{|c|}{ Variables en la ecuación } \\
\hline & & \multirow[b]{2}{*}{$\mathrm{B}$} & \multirow[b]{2}{*}{ E.T. } & \multirow[b]{2}{*}{ Wald } & \multirow[b]{2}{*}{ g } & \multirow[b]{2}{*}{ Sig. } & \multirow[b]{2}{*}{$\operatorname{Exp}(B)$} & \multicolumn{2}{|c|}{ I.C. $95.0 \%$ para EXP(B) } \\
\hline & & & & & & & & Inferior & Superior \\
\hline \multirow{7}{*}{$\begin{array}{l}\text { Paso } \\
1\end{array}$} & Cofam & -.092 & .017 & 28.940 & 1 & .000 & .912 & .882 & .943 \\
\hline & tasad75 & 1.655 & .019 & 7987.281 & 1 & .000 & 5.231 & 5.045 & 5.424 \\
\hline & radep50 & .503 & .011 & 2004.772 & 1 & .000 & 1.653 & 1.617 & 1.690 \\
\hline & pobext & 1.171 & .008 & 19204.678 & 1 & .000 & 3.227 & 3.174 & 3.281 \\
\hline & nopob & -.895 & .009 & 8885.338 & 1 & .000 & .409 & .401 & .416 \\
\hline & riqueza1 & -1.029 & .018 & 3190.672 & 1 & .000 & .357 & .345 & .370 \\
\hline & Constante & -2.494 & .006 & 154804.3 & 1 & .000 & .083 & & \\
\hline
\end{tabular}

a. Variable(s) introducida(s) en el paso 1: Cofam, tasad75, radep50, pobext, nopob, riqueza1.

Donde:

Cofam $=$ Cobertura

Tasad75 $=$ Desempleo

Radep50 = Desempleo Equivalente

Pobext $=$ Pobreza Extrema

Nopob $=$ No pobreza

Riqueza1 $=$ Riqueza 
El resultado final del modelo puede expresarse de esta forma:

$\operatorname{Ln}(p / q)=-0.092$ Cobertura+ 1.655Desempleo + 0.503Desempleo Equivalente +

1.171 Pobreza Extrema - 0.895 No Pobreza - 1.029 Riqueza

\section{Interpretación de los resultados}

En base a toda la información analizada es posible afirmar que la falta de cobertura de las necesidades promedio de las familias salvadoreñas, es decir de la fuerza de trabajo, es uno de los principales factores que impulsan la migración en el país, ya que muchas de ellas se ven en la necesidad de buscar en otros países, el empleo y el ingreso necesario para lograr una calidad de vida en la que puedan obtener educación, vivienda entre otros, que la economía local no les puede garantizar.

No obstante, no es solamente la cobertura del valor la fuerza de trabajo el factor que determina la migración externa, también figuran la pobreza extrema, la no pobreza y el desempleo como variables importantes. La combinación de estos factores explican una mayor probabilidad de que las familias migren: esto se traduce en que la mayoría de las fami- lias ven limitadas sus oportunidades de obtener un empleo digno y bien remunerado, lo que incrementa la tendencia a migrar.

¿Qué características tiene la economía salvadoreña que no permite que se absorba la población económicamente activa dentro de empleo con jornada completa y bien remunerada? Esta en una pregunta que no se podría contestar únicamente con este modelo, sino se tendría que analizar más a fondo políticas implementadas a lo largo de los años por el Estado, pero lo que si bien es cierto es que el modelo claramente refleja que el subempleo es uno de los grandes problemas de la economía, tal como lo plantea el PNUD.

Esto permite afirmar que a falta de empleo, las personas aceptan estar subempleada o buscan la alternativa de irse del país. 


\section{Conclusiones}

El fenómeno migratorio se ha convertido en una temática primordial en El Salvador dado el peso que tienen en la economía las ayudas por remesas provenientes principalmente desde Estados Unidos, convirtiéndose en la principal fuente de divisas a nivel nacional y apoyando la estabilidad macroeconómica.

Consecuentemente esta enorme entrada de dinero "gratis" ha incentivado el consumo nacional financiando los altos montos de importaciones que se realizan cada año, desincentivando la producción nacional e incrementando cada vez la brecha comercial.

Sin embargo, la migración externa también ha incrementado los ingresos en varios sectores de la economía, dadas las nuevas necesidades a las que se enfrentan los migrantes, tales como las de comunicación con sus familiares, el transporte aéreo y transferencias de remesas; asimismo ha generado mayores ingresos en rubros como el turismo étnico, el consumo de bienes nostálgicos y el de vivienda, permitiendo que estos sectores hayan incrementado su aporte dentro del PIB.

Por otro lado, la migración y sus consecuentes flujos de remesas, han permitido aliviar la pobreza de muchas familias a nivel nacional, pero es el área rural la que más se ha visto beneficiada, pues existe ahí mayor pobreza que en el área urbana. Las familias utilizan estos ingresos para satisfacer sus necesidades promedio como educación, salud, vivienda, consumo, etc., las cuales no le garantiza la economía nacional.

Varias teorías han intentado explicar el fenómeno migratorio a nivel general, la mayoría de ellas concuerdan que las principales motivaciones que los individuos tienen para migrar están relacionadas con la búsqueda de mejores condiciones económicas y niveles de calidad de vida más altos.

Sin embargo, se ha intentado plantear un modelo que tome en cuenta variables más profundas de las condiciones de vida de los países expulsores, las cuales podrían ser las causas principales de la migración, tomando en cuenta la cobertura de las necesidades que en promedio las familias tienen en el lugar de origen y la migración como una decisión tomada como unidad familiar.

Finalmente, el modelo econométrico aplicado permite llegar a la conclusión que el principal factor que el país posee en cuanto a generadores de migración externa es la falta de absorción de la fuerza de trabajo local y la pobreza, lo que 
significa que muchos miembros del hogar acuden a la alternativa migratoria para ir en busca de las oportunidades que les son negadas en su nación.

Asimismo, el modelo permite ver que las familias no pobres que no cubren la canasta de mercado también ven en peligro su sostenimiento y reproducción en condiciones de bienestar, buscando en el exterior el empleo y los ingresos necesarios para sostener una calidad de vida adecuada.

Contrario a lo que se cree en muchos documentos, en este estudio la pobreza extrema es uno de los factores principales, que junto a otros, impulsan la migración, por lo que se tendría que hacer un estudio más profundo acerca del tema y su relación con la migración externa en El Salvador.

\section{Bibliografía}

- Alfaro Villegas, G.G. Escoto Castillo A.R y Sánchez Barrera E.M. (2006) "La Heterogeneidad Estructural y la Dinámica Laboral en El Salvador" Tesis de Licenciatura (En Línea) http:// churropolis.org/aniux/Tesis/

- Alvarado Pineda S.A., (1987) "Análisis global de la matriz insumo producto e identificación del modelo económico salvadoreño" Tesis de Licenciatura, El Salvador. Facultad de Cien- cias Económicas, Universidad Centroamericana José Simeón Canas.

- Álvarez Ramírez J.A. y Méndez Maradiaga C.B., (2004) "Visión alternativa a la migración salvadoreña: Las otras variables que se están afectando" (Aproximación Empírica) Tesis de Licenciatura, El Salvador. Facultad de Ciencias Económicas y Sociales, Universidad Centroamericana José Simeón Canas.

- Aroca González, Patricio; Lufin Varas, Marcelo (Marzo 1998). "Migración Interregional en Países en Desarrollo Bajo Regímenes de Mercado con Especial Énfasis al caso de Latinoamérica". Universidad Católica del Norte, Facultad de Economía y Administración Instituto de Economía Aplicada Regional Antofagasta - Chile (En línea). Fuente: http://www.tamuk.edu/ geo/urbana/fall2000/migration. pdf

- BCR. "Metodología de Calculo e Importancia de as Remesas Familiares en El Salvador. (En líanea). http://www. cemla-remesas.org/PDF/ seminariomx/0510MX-ES-PPTElSalvador.pdf

- Berthier, A., (2007) El sistema de Referencias Harvard. En Conocimiento y Sociedad.com. 


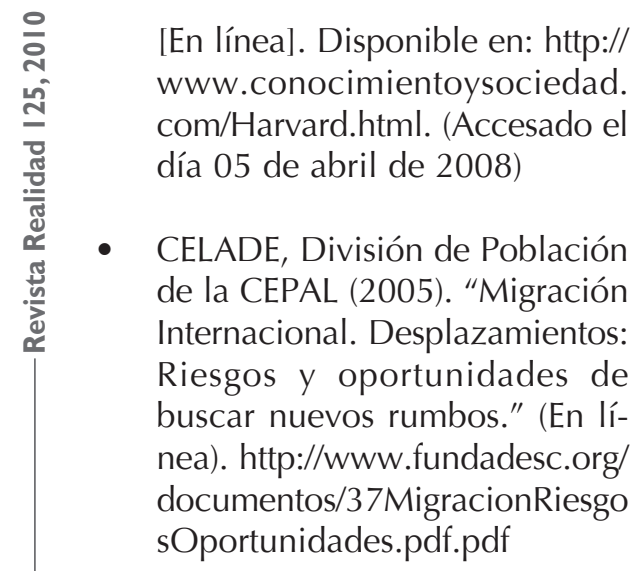

- CNN Noticias. "Las Remesas en América Latina crecen lento en 2007" 11 de Marzo de 2008. (En línea). http:// www.cnnexpansion.com/economia/2008/03/11/las-remesasa-al-crecen-lento-en-2007

- Comunidades Pan Americanas (2005). Proyecto "Manos Unidas por El Salvador". (En línea). http://www.panamericancommunities.org

- Dada Hirezi), Héctor (1978). La Economía de El Salvador y la Integración Centroamericana 1945-1960. $1^{\text {a }}$ Edición. UCA Editores.

- Definición.org. (Mayo 2008). Definición de Migración. http:// www.definicion.org/migracion

- FCC (Federal Communications Comission). Wireline Competition Bureau Statistical Reports (formerly FCC-State Link) (en linea). http://www.fcc.gov/wcb/ iatd/stats.html

- FESPAD "El Observatorio de las Políticas Públicas y los DESC". Prontuario Socio-Económico No.3, 2007.

- Fondo Internacional de las $\mathrm{Na}$ ciones Unidas de Auxilio a la Infancia (UNICEF) 2005. "Pobreza Extrema y objetivos del Milenio" (En línea) http://www. unicef.org

- FUNDASAL (Fundación Salvadoreña de Desarrollo y Vivienda Familiar) (Febrero 2006). "Efectos de las remesas en el sector vivienda". (En línea). http://www.fundasal.org.sv/documentos/cartas_urbanas/carta_urbana_131.pdf

- FUSADES (2005). "Heterogeneidad de las remesas: Implicaciones para el desarrollo de productos financieros". (En línea). http://www.fusades.org. sv/general.asp?id=162

- García Pelayo, Ramón (2005). "Larousse Diccionario Básico". $1^{\text {a }}$ Edición. Ediciones Larousse S.A. de C.V.

- Glosario. net. (Mayo 2008). Migración. http://ciencia. glosario.net/agricultura/ migraci\%F3n-11543.html 
- Hernández, Xochitl Iztel (2006) "Las Remesas colectivas como instrumento potencial de desarrollo. Estudio de Caso" Tesis de Licenciatura, El Salvador. Facultad de Ciencias Económicas y Sociales, Universidad Centroamericana José Simeón Canas.

- Kozak, Roberto (2006). "El tratamiento Multilateral de las Migraciones en el Ámbito Iberoamericano". II Tratamiento Multilateral. (En Línea).http:// www.crmsv.org/SEGIB/9\%20 quintaParte.pdf

- La Prensa Gráfica. "Financiarán con nuevo impuesto" 26 de Junio de 2008. (En línea). http:// www.laprensagrafica.com/nacion/1087828.asp

- Márquez, Marielos; Cuellar, Amelia E.; Guevara, Miguel A. (2006) "Economía de remesas del trabajo: eficiencia de la racionalidad solidaria" ECA, Vol. 61 No.695. Septiembre 2006.

- Menjívar, Rafael (1980). Acumulación originaria y desarrollo del capitalismo en El Salvador. $1^{\text {a }}$ Edición. Editorial Universitaria Centroamericana (EDUCA).

- MINEC, INFORME ANUAL 2005 (En línea). http://www.minec.gob.sv/media\%5Cdownloa $\mathrm{ds} \% 5$ CPresentaciones $\% 5$ CInfor
me\%20Anual\%20Inflacion\%20 2005.pdf

- Ministerio de Relaciones Exteriores. Noticias.

- "Viceministra anuncia resultados de encuesta de preferencias de vivienda en hogares salvadoreños que reciben remesas". 19 de Septiembre de 2006. (En línea). http://www.rree.gob. sv/sitio/sitiowebrree.nsf/pages/ viceminifervivi06

- Montesino, Mario Salomón, (2000) "La dinámica salariosproductividad y el desarrollo económico en El Salvador", Revista Realidad, Julio-Agosto 2000 No. 76

- Montesino, Mario Salomón, (2006) "Enfoque teórico de la economía abierta de servicios y la economía de remesas del trabajo" ECA, Vol. 661 No. 695, Septiembre 2006.

- Montesino, Mario Salomón, (2007) "Cobertura del Valor de la Fuerza de Trabajo: racionalidad productiva frente a racionalidad de la plusvalía" ECA, Vol. 62 No. 707, Septiembre 2007

- Organización de las Naciones Unidas (ONU), Comité de Derechos Económicos, Sociales y Culturales (2006) "Observaciones Finales" 


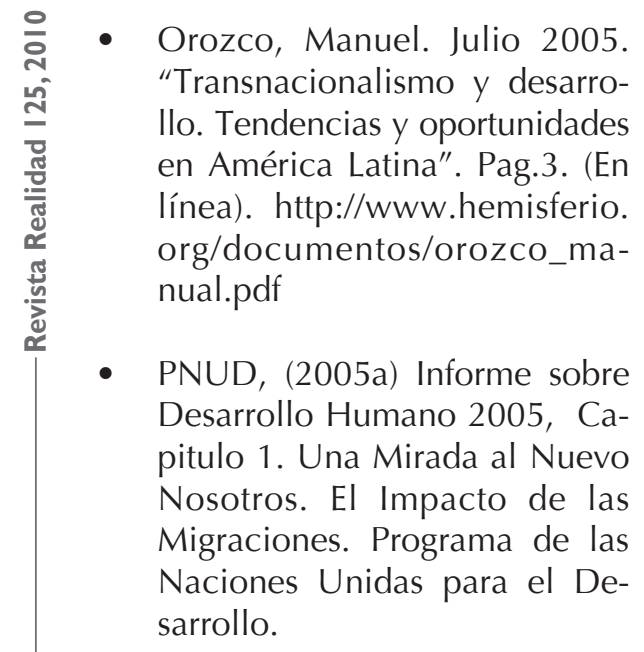

- PNUD, (2005b) Informe sobre Desarrollo Humano 2005, Capitulo 2. Una Mirada al Nuevo Nosotros. El Impacto de las Migraciones. Programa de las Naciones Unidas para el Desarrollo.

- PNUD, (2005c) Informe sobre Desarrollo Humano 2005, Capitulo 7. Una Mirada al Nuevo Nosotros. El Impacto de las Migraciones. Programa de las Naciones Unidas para el Desarrollo.

- PNUD, (2005d) Informe sobre Desarrollo Humano 2005, Capitulo 4. Una Mirada al Nuevo Nosotros. El Impacto de las Migraciones. Programa de las Naciones Unidas para el Desarrollo.

- PNUD, (2005e) Informe sobre Desarrollo Humano 2005, Ca- pitulo 5. Una Mirada al Nuevo Nosotros. El Impacto de las Migraciones. Programa de las Naciones Unidas para el Desarrollo.

- Programa Salvadoreño de Investigación sobre Desarrollo y Medio Ambiente (PRISMA 2006) "Dinámica Migratoria, Medios de Vida Rurales y Manejo de Recursos Naturales" http://www.prisma2.org.sv/web/ publicacion_detalle.php?id=92

- Ramírez Rodríguez, C.P. y Zaldana Espinoza S.E., (2005) "Desequilibrios territoriales en la economía salvadoreña" Tesis de Licenciatura, El Salvador. Facultad de Ciencias Económicas y Sociales, Universidad Centroamericana José Simeón Canas.

- Ramírez Rodríguez, C.P. y Zaldana Espinoza S.E., (2005) "Desequilibrios territoriales en la economía salvadoreña" Tesis de Licenciatura, El Salvador. Facultad de Ciencias Económicas y Sociales, Universidad Centroamericana José Simeón Canas.

- Rocha, José Luis (Julio 2003). "¿Por qué se van?, la onda migratoria y las teorías que la explican" Revista Envío digital Número 256. (En línea) http://www.envio.org.ni/articulo/1241 
- Secretaría de Gobernación. "Los Enfoques de la Migración". (En línea). http://www.conapo. gob.mx/publicaciones/intensidadmig/cap02.pdf

- Teorías del Desarrollo. La Evolución del Pensamiento sobre Desarrollo. (En línea) http:// www.insumisos.com/lecturasinsumisas/Teorias\%20del\%20 Desarrollo.pdf)

- Teorías Explicativas de los Flujos Migratorios. Capítulo 1 (En línea). http://www.oberaxemtas. upcomillas.es/Publicaciones/ Libros/mercado/capitulo1.PDF

\section{NOTAS}

1 Sir W. Arthur Lewis (1915-1990) Economista británico, nacido en Santa Lucía. Obtuvo el Premio Nobel de Economía en 1979, por su investigación enfocada a los problemas de los países en desarrollo. Fue asesor de la Comisión Económica de las Naciones Unidas para Asia y el Lejano Oriente y Presidente del Banco de Desarrollo del Caribe (Universidad de Málaga, Enciclopedia Virtual (En línea) Disponible en: http://www.eumed.net/cursecon/ economistas/lewis.htm, (Accesado el día 12 Junio de 2008)).

2 Dr. Mario Salomón Montesino, Catedrático Universidad Centroamericana "José Simeón Cañas"
- Universidad de Málaga, Enciclopedia Virtual (En línea) Disponible en: http://www.eumed. net (Accesado el día 12 Junio de 2008)).

- Vega, Lilian, (2002) "Diáspora Salvadoreña: iresultado del pobre desempeño de la economía o elemento constituyente del modelo que configura?" en ECA, año LVII No. 648. Octubre 2002 .

- Wooldridge, Jeffrey 2001. "Introducción a la Econometría". $1^{\text {a }}$ Edición. Thomson Learning. Mexico.

3 Para mayor referencia de la definición de Cobertura de la Fuerza de Trabajo, remitirse a Montesino, Mario Salomón, (2006) "Enfoque teórico de la economía abierta de servicios y la economía de remesas del trabajo" ECA, Vol. 661 No. 695, Septiembre 2006.

La canasta de mercado se define como el conjunto de artículos (considerando algunos servicios), que representan el patrón de consumo promedio de un hogar urbano. (MINEC, 2005)

$5 \quad$ El grado esperado de la cobertura dependerá de las necesidades de cada familia, la cuales a su vez dependerá si es urbana o rural, grande o pequeña, etc. 


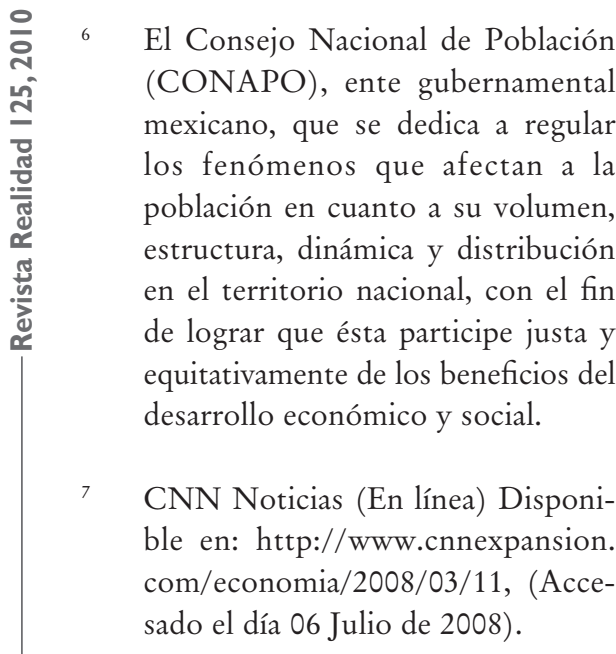

$8 \quad$ Fundación Intervida (En línea) Disponible en: http://www.intervida. org/, (Accesado el día 24 Junio de 2008)).

9 Tales como: Privatización de la Banca, reducción de impuestos a las importaciones, maquilas como recintos fiscales.

10 Dato por elaboración propia: Total remesas / Total importaciones, basados en datos de BCR en línea.
No se pudieron encontrar datos en USD enfocados únicamente a este sector, ya que los datos que se manejan en las cuentas nacionales del sector incluye transporte de carga y almacenamiento.

12 Para mayor referencia de la estimación del dato del costo promedio de remisión de remesas desde Estados Unidos, remitirse al Informe de Desarrollo Humano PNUD 2005, capítulo 4, página 18 o al Anexo estadístico

Dato tomado de Informe: Orozco, Manuel. Julio 2005. “Transnacionalismo y desarrollo. Tendencias y oportunidades en América Latina”. Pag.3. (En línea). http://www. hemisferio.org/documentos/orozco_manual.pdf o ver tabla anexo B2

14 Dato tomado de Artículo "De Moda las de \$50,000”, del periódico La Prensa Gráfica, edición 15 de Mayo 2007. Ver tabla anexo B3

15 Para la realización del modelo econométrico se utilizó la base de la EHPM del 2006 